\title{
Effects of harvesting intensity and site conditions on biomass production of northern Patagonia shrublands
}

\author{
Matías G. Goldenberg ${ }^{1,2}$ (D) Facundo J. Oddi ${ }^{1,2} \cdot$ Mariano M. Amoroso $^{1,2} \cdot$ Lucas A. Garibaldi $^{1,2}$
}

Received: 2 September 2019 / Revised: 29 April 2020 / Accepted: 19 May 2020

c) Springer-Verlag GmbH Germany, part of Springer Nature 2020

\begin{abstract}
Forest biomass with energy purpose is gaining importance. Although there is a lot of information about afforestation for energy purpose, native resource management for biofuel production is a less studied topic. Consequently, generating information about management of local forest types that have potential for providing biomass for energy, such as resprouting shrublands, becomes a priority objective. We evaluated the effects of harvesting intensity on coppice growth in three resprouting shrublands with contrasting site conditions in northern Patagonia (Argentina). At each site, three harvesting treatments in strips of increasing width were randomly assigned to six permanent plots of 31.5×45 m during 2013-2014. Four years after, we measured resprouts (number and size of stems) of the five native dominant species. We found that almost all species responded to harvesting intensity by enhancing the coppice growth rates. Nonetheless, species showed different strategies for resource obtention. When analyzing at the community level, the response to harvesting intensity was consistent among the hillside sites, but conservative in the valley bottom site with the worst environmental conditions. Due to the high response of these species to harvesting intensity, we conclude that intense shrubland management for biomass commercialization could be a viable option depending on site conditions.
\end{abstract}

Keywords Bioenergy $\cdot$ Coppicing $\cdot$ Woodlands

\section{Introduction}

Sustainable use of renewable energy sources is essential to face current global change challenges. While energy use of forest biomass reduces the dependency on non-renewable energy sources, and thus on greenhouse gas emissions, it also generates pressure on forest resources; therefore,

Communicated by Lluís Coll.

Electronic supplementary material The online version of this article (https://doi.org/10.1007/s10342-020-01292-6) contains supplementary material, which is available to authorized users.

Matías G. Goldenberg

mgoldenberg@unrn.edu.ar

1 Instituto de Investigaciones en Recursos Naturales, Agroecología y Desarrollo Rural, Universidad Nacional de Río Negro, Mitre 630, San Carlos de Bariloche, Río Negro, Argentina

2 Instituto de Investigaciones en Recursos Naturales, Agroecología y Desarrollo Rural, Consejo

Nacional de Investigaciones Científicas y Técnicas, San Carlos de Bariloche, Río Negro, Argentina sustainable management plans are necessary. Shrublands have suitable properties for energy production, and biomass derived from these ecosystems is gaining importance (González-González et al. 2017). Indeed, this forest type has the potential to complement biomass derived from clearing, thinning or pruning, with that obtained from plantations of fast-growing species (Karp and Shield 2014). In fact, the competition between land area for short rotation coppice plantations and food products has discouraged this first option (Glithero et al. 2013), leaving natural forests with coppicing species as a more desirable solution (Spinelli et al. 2017). However, shrubland management is one of the least studied topics in forest sciences, and therefore, local information becomes relevant to achieving sustainable solid biofuel production from these natural woody communities (Avohou et al. 2010).

Firewood has been the main fuel resource for humanity since its beginning, and at the present, it is the main source of energy in rural and low-income communities, especially in developing countries. It is used for heating and cooking and represents the main fuel resource for one-third of the world's population (FAO 2008). Although using wood for 
energy is not new, solid biofuel is being the focus of novel research as renewable fuel resource (Abbasi and Abbasi 2010). In this sense, the energy derived from solid biomass is beneficial for the environment since it is considered neutral in terms of the emission of greenhouse gases (mainly $\mathrm{CO}_{2}$ ) according to the European Union (European Commission 2003). In addition, when obtained under sustainable forest management, it may have also maintained or even increased the provision of certain ecosystem services (e.g., fire control) (Regos et al. 2016).

In northwest Patagonia, Nothofagus antarctica ((G. Forst.) Oerst.) forms typical Mediterranean-type climate shrublands. They are the most diverse ecosystems in the region (Speziale et al. 2010), and while these forest types have been historically burned for cattle production (Dezzotti and Sancholuz 1991), at present they must be managed sustainably ensuring the provision of ecosystem services (sensu National Law 26.331). Most of the woody species that compose north Patagonia shrublands are heliophiles and resprouters (Rusch et al. 2017), which gives them an adaptation to fire, the most recurrent disturbance in the region (Kitzberger and Veblen 1999). These species exhibit fast initial growth after such disturbance (Landesmann et al. 2016) and their woods are used for energy (firewood) by local people. Considering the productive, social and environmental value of native shrublands of north Patagonia, the management of forests with energy purposes should be based on partial cuttings, leaving permanent forest cover to ensure the provision of ecosystem services and system sustainability (sensu National Law 26.331). In this way, harvesting in strips is an innovative management approach in north Patagonia that could be both environmentally and economically sustainable (Goldenberg et al. 2018).

A key aspect of management is the growth response to silvicultural interventions. Currently, knowledge of how the coppice growth responds to management in native tree species of north Patagonia is limited (Reque et al. 2007; Gyenge et al. 2009; Goldenberg et al. 2018). Main studies focusing on growth of $N$. antarctica shrublands in north Patagonia have concentrated on unmanaged forests (Gyenge et al. 2008; Landesmann et al. 2016) analyzing post-fire vegetation dynamics (Tiribelli et al. 2018).

Quantifying the response on shrubland growth to management in different sites (species composition and site conditions) would allow obtaining a greater understanding of ecosystem resilience and designing silvicultural systems with energy purpose. In addition, biomass management schemes must consider the socioeconomic characteristics of forest owners. For instance, shrubland management based on the use of light equipment for harvesting (e.g., chainsaw) could be a viable option for small and medium forest enterprises and an alternative or complement to livestock production.
Our objective was to analyze the response of coppice growth to a harvesting intensity gradient under different site conditions in northern Patagonian shrublands. We focus on the effects of harvesting intensity and site on: (i) biomass components affecting volume per plant (number of stems and their diameter and height) and (ii) mean annual biomass production. We used an experimental approach replicated on three contrasting sites applying a continuous cover silvicultural system based on systematic strip harvesting for biomass production.

\section{Materials and methods}

\section{Study area and experimental sites}

The northern Patagonian region of Argentina has a Mediterranean-type climate (Keeley et al. 2011), with an annual precipitation that ranges from 920 to $1300 \mathrm{~mm}$ in the $N$. antarctica distribution. Average annual temperatures range from 8 to $9{ }^{\circ} \mathrm{C}$, with an annual average maximum temperature of $15^{\circ} \mathrm{C}$ and minimum temperature of $1.5^{\circ} \mathrm{C}$. The annual relative humidity is $65 \%$, and the annual dew temperature is $2{ }^{\circ} \mathrm{C}$. Frosts occur about 120 days a year, but frost presence is longer in valley bottoms (Chauchard et al. 2015).

Three sites with contrasting environmental conditions in the province of Rio Negro, Argentina, were chosen to conduct the study (Fig. 1). The choice was based on site exposure, one of the main environmental factors driving shrubland physiognomy in this region. In southern exposure hillsides, soils are deeper and have greater development and higher moisture retention than northern hillsides, where soils are drier because they are exposed to the dominant northwestern winds and intense summer droughts (Chauchard et al. 2015). Consequently, productivity is determined by the position of sites in the landscape: Southern exposure sites are more productive than northern ones, but both are more productive than some valley bottom sites where environmental condition can be limiting. Hence, one site was located on a southern slope (high productivity), another on a northern slope (medium productivity) and the remaining on a valley bottom (low productivity). Vegetation was dominated by mixed $N$. antarctica shrublands in the high- and mediumproductivity sites; where Schinus patagonicus ((Phil.) I.M. Johnst.), Lomatia hirsuta ((Lam.) Diels ex Macbr.), Diostea juncea ((Gillies \& Hook.) Miers) and Embothrium coccineum (J.R. Forst. \& G. Forst) codominate the stand and by pure $N$. antarctica shrublands in the low-productivity site (Table 1); the only woody species present in all three sites was $N$. antarctica. In the high- and medium-productivity sites, soils were dominated by the group of Hapludands (USDA 2014), with dark color, sandy texture, lose structure and abundant presence of roots. The medium-productivity 
Fig. 1 Black triangles indicate the three experimental sites along Rio Negro province (Argentina). The shrubland distribution is dark gray, and the tall forest is light gray

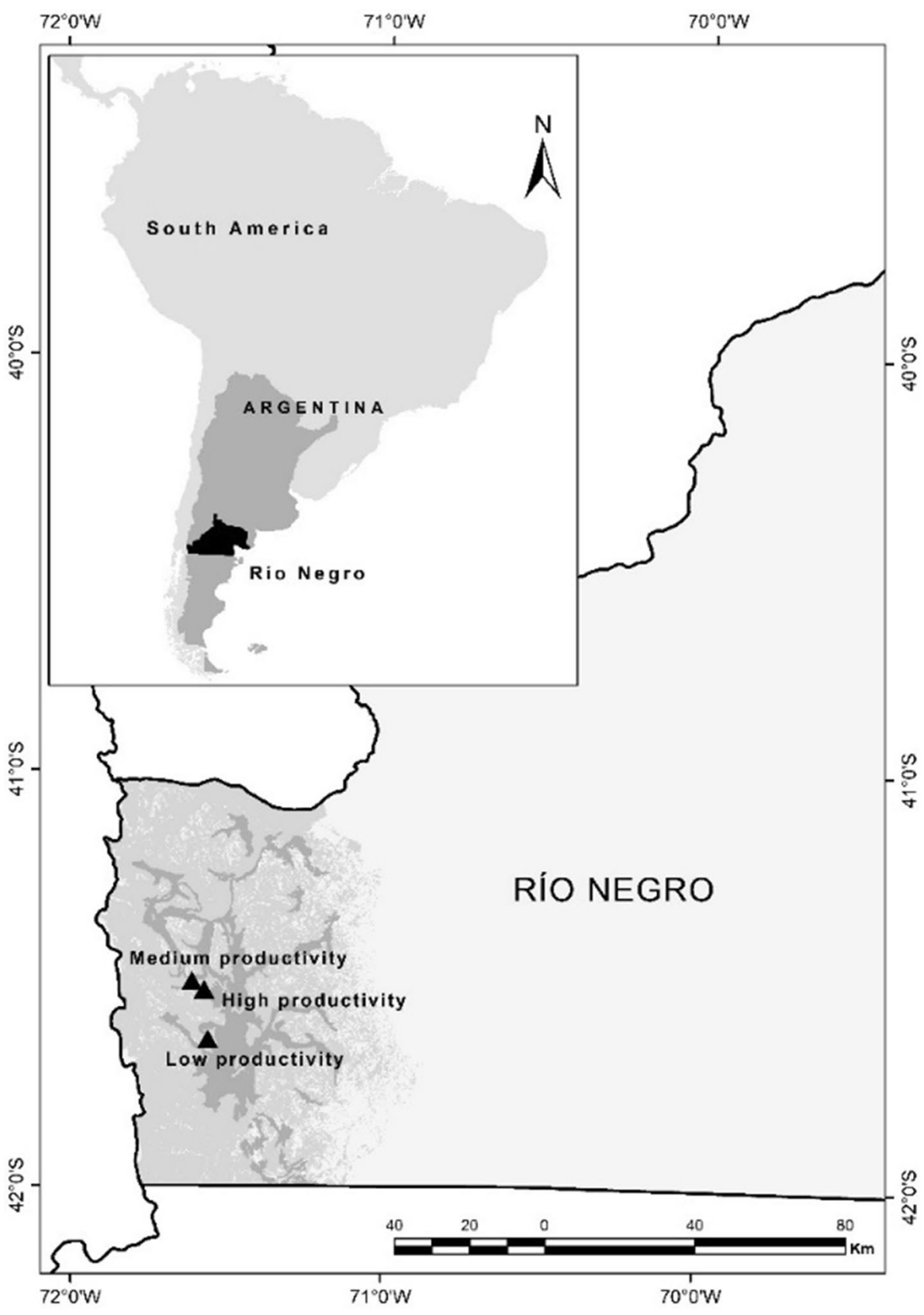

site had shallower soils and presence of rocks. The groups of Udivitrands (USDA 2014) were dominant in the lowproductivity site with ocher color, poor abundance of roots and less soil depth. Elevation across sites ranges from $790 \mathrm{~m}$ to $840 \mathrm{~m}$. Table 1 summarizes the environmental and stand features of the three sites.

\section{Harvesting treatments}

At each site six $31.5 \mathrm{~m} \times 45 \mathrm{~m}$ long-term experimental plots were established on each site (total plots $=18$ ) and protected from cattle. Between 2013 and 2014, all plots were harvested in six strips of increasing width $(1.5 ; 2.5$ and $3.5 \mathrm{~m}$, along the plot) resulting in approximately $30 \%, 50 \%$ and $70 \%$ of shrub cover removal, respectively. All biomass of the strip was harvested, and stems with diameter greater than $4 \mathrm{~cm}$ were classified as firewood, leaving smaller branches and leaves in the intervention strips (Table S1-1). The very few Austrocedrus chilensis ((D. Don) Pic. Serm. \& Bizzarri) individuals present were not harvested to preserve the long-term conifer component. All firewood cubic volume was measured (Table 1). Mean annual volume increment estimations (including all treatments) of firewood were significantly different between 
Table 1 Study site characteristics

\begin{tabular}{|c|c|c|c|}
\hline \multirow[t]{2}{*}{ Site and stand variables } & \multicolumn{3}{|l|}{ Site productivity } \\
\hline & High & Medium & Low \\
\hline Slope orientation & South & North & - \\
\hline Topographic position & Low hillside & Low hillside & Valley bottom \\
\hline Soil group & Hapludands & Hapludands & Udivitrands \\
\hline Soil depth (cm) & 125 & 55 & 90 \\
\hline Stand age (years) & $\sim 50$ & $\sim 50$ & $\sim 30$ \\
\hline Stem density $\left(\right.$ stems ha $\left.{ }^{-1}\right)$ & $9847 \pm 696$ & $8554 \pm 1591$ & $37,129 \pm 354$ \\
\hline N. antarctica dominant height (m) & $6.1 \pm 0.7$ & $3.4 \pm 0.4$ & $2.5 \pm 0.1$ \\
\hline Firewood volume $\left(\mathrm{m}^{3} \mathrm{ha}^{-1}\right)^{*}$ & $149.5 \pm 22.9$ & $77.7 \pm 20.2$ & $9.3 \pm 1.8$ \\
\hline $\operatorname{MAI}\left(\mathrm{m}^{3} \mathrm{ha}^{-1}\right.$ year $\left.^{-1}\right) * *$ & $3.6 \pm 0.3^{\mathrm{a}}$ & $1.8 \pm 0.3^{\mathrm{b}}$ & $0.4 \pm 0.1^{\mathrm{c}}$ \\
\hline \multirow[t]{5}{*}{ Species composition $(\%)$} & N. antarctica $(35)$ & N. antarctica (33) & N. antarctica $(100)$ \\
\hline & L. hirsuta (5) & L. hirsuta (16) & \\
\hline & S. patagonicus (35) & S. patagonicus (28) & \\
\hline & D. juncea (8) & D. juncea (13) & \\
\hline & E. coccineum (18) & E. coccineum $(11)$ & \\
\hline
\end{tabular}

Mean values \pm standard errors

*Mean volume for all harvesting intensities $(30,50,70 \%)$ extrapolated to hectare \pm standard error

**Estimated mean annual increment considering the solid volume of firewood of all plots (6 plots per site) and stand age. Different letters indicate significant statistical differences using Tukey test after ANOVA ( $p$ value $<0.001$ )

sites reflecting the different site conditions for biomass production of the selected sites (Table 1).

\section{Field and laboratory measures}

We defined five species of interest these being those that at the time of harvesting had a stem base diameter greater than $4 \mathrm{~cm}$ (Table 1). During the summer of 2018, in the harvest lines, four plants of each of the five species of interest were randomly chosen in each plot (in total 20 plants per plot in the high- and medium-productivity sites and 4 plants per plot in the low-productivity site with only $N$. antarctica), and the number of resprouting stems per stool was counted in each one. Of these stems, five were randomly selected and stem base diameter (SBD, $3 \mathrm{~cm}$ from the insertion point to the stool) and total height ( $\mathrm{SH}$ ) were measured to estimate stem volume (SV). Volume was used as a measure of biomass because it is the most used measure of forest growth and commercialization in the region (Goldenberg et al. 2018).

Also, between 10 and 17 resprouting stems per species, covering the existing diameter classes, were randomly harvested. The SBD and $\mathrm{H}$ of the harvested stems were recorded (SBDs and Hs, respectively), and the leafless volume of the harvested stems was estimated (SV) in the laboratory using five sections according to Huber's method (Cruz de León and Uranga-Valencia 2013):

$\mathrm{SV}=\frac{\pi}{4} 0.2 \times L\left(d_{0.1}^{2}+d_{0.3}^{2}+d_{0.5}^{2}+d_{0.7}^{2}+d_{0.9}^{2}\right)$ where $L$ indicates the length of stem and $\mathrm{d}$ is the diameter at the half length of each of the five sections. To estimate the volume of the non-harvested stems measured in the interventions strips (SV), regression models between SV and SDB and $\mathrm{H}$ from harvested stems were fit (see "Volume equations" section).

SBD, SH and SV (estimated through volume models) were divided by the number of growing periods (October-May) elapsed since coppicing for calculating their mean annual increment (MAI). These resulted in 3.3, 3 and 4 periods of growth for the site of high, medium and low productivity, respectively. For each species, plant biomass production (PVMAI; $\mathrm{cm}^{3}$ plant $^{-1}$ year $^{-1}$ ) was obtained by multiplying stem volume (SV-MAI; $\mathrm{cm}^{3}$ stem $^{-1}$ year $^{-1}$ ) by number of stems per stool resprouting ( $n$; stems plant ${ }^{-1}$; Table 2 ). Then, biomass production at the plot level (BV-MAI; $\mathrm{m}^{3} \mathrm{ha}^{-1}$ year $^{-1}$ ) was obtained as:

$(\mathrm{BV}-\mathrm{MAI})_{i}=\sum_{t: 1}^{5}\left(\mathrm{PV}-\mathrm{MAI}_{t i} \times \mathrm{Pl}_{t i}\right)$

i: plot $(n=18)$; t: species (N. antarctica, S. patagonicus, D. juncea, L. hirsuta, E. coccineum); and $\mathrm{Pl}$ : number of plants per ha. 
Table 2 Biomass growth components

\begin{tabular}{llll}
\hline Biomass components & Description & Unit & Level \\
\hline SH-MAI & Stem height-MAI & $\mathrm{cm} \mathrm{stem}^{-1}$ year $^{-1}$ & \\
SBD-MAI & Stem base diameter-MAI & $\mathrm{mm} \mathrm{stem}^{-1}$ year $^{-1}$ & Stem \\
SV-MAI & Stem volume-MAI & $\mathrm{cm}^{3} \mathrm{stem}^{-1} \mathrm{year}^{-1}$ & \\
$n$ & Number of stems per stool & stems plant $^{-1}$ & Plant (stool) \\
PV-MAI & Plant volume-MAI & $\mathrm{cm}^{3}$ plant $^{-1}$ year $^{-1}$ & \\
BV-MAI & Biomass volume-MAI & $\mathrm{m}^{3} \mathrm{ha}^{-1}$ year $^{-1}$ & Plot \\
\hline
\end{tabular}

Each of these dependent variables was analyzed as a function of harvesting intensity, site productivity and interactions for each species except analyses at the plot level (BV-MAI) that consider all species in the plot (Eq. 2). MAI = Mean annual increment

\section{Data analysis}

\section{Volume equations}

The volume equations for each species were fitted using multiple linear regressions with the $g l s()$ function from the nlme package (Pinheiro et al. 2020). The models considered the following quantitative predictors: SBDs, squared SBDs, Hs and squared Hs. The best fitting models were selected based on Akaike information criterion (AIC) using the dredge() function from the package MuMin (Barton 2019). The assumptions of homoscedasticity and normality were verified by visual evaluation of the residual scatter plots (residual vs. predicted values) and Shapiro-Wilk and Kolmogorov-Smirnov tests (shapiro.test and ks.test). When necessary, variances were modeled using variance functions (VarPower() as a function of predicted stem volume).

\section{Biomass production}

For analyzing the effect of harvesting intensity and site productivity on each biomass component (Table 2), general and generalized linear mixed-effects models were fitted. For continuous responses (SH-MAI, SBD-MAI, SV-MAI (estimated from fitted volume models), PV-MAI, BV-MAI; see Table 2), normal errors were assumed and variances were modeled when necessary. In the case of count data (number of stems per stool), a binomial negative error structure was used because data were over-dispersed. Species were analyzed separately; that is, one model per species was fitted in each response variable. In all the cases, the models were fitted with harvesting intensity (quantitative), including linear and squared terms to account for possible nonlinear responses, site (categorical) and interactions, as fixed effects. Plot was considered as a random effect to represent the dependency among observations induced by the spatial nesting. Model selection was performed under a multi-model inference framework (Burnham and Anderson 2002, Garibaldi et al. 2017). AIC was used as a parsimony measure to decide which terms of the global models were important
(Burnham et al. 2011), and relative importance values, which sum the 'Akaike weights' over all models including the explanatory variable, were calculated. Finally, correlation matrix were obtained for SV-MAI, $n$ and PV-MAI for understanding the main drivers in plant responses.

All data analysis was carried out in R 3.6.3 (R Core Team 2020). Models were fitted with the $\operatorname{lme}($ ) function of the nlme package (Pinheiro et al. 2020) and the glmmadmb() function included in the glmmADMB package (Skaug et al. 2016). Model selection was carried out using the dredge() and the importance() function, both from the package MuMin (Barton 2019). Model assumptions were checked by visual evaluation of residual scatter plots (residual vs. predicted values) and Shapiro-Wilk and Kolmogorov-Smirnov tests (shapiro.test and ks.test).

\section{Results}

\section{Volume equations}

For all the species, as expected, SBD and $\mathrm{H}$ were included in the selected models. All the selected models showed good statistical fitness (Fig. 2). The SBD ranged from 1.6 to $30.5 \mathrm{~mm}$ for $N$. antarctica, 2.8 to $22.5 \mathrm{~mm}$ for $S$. patagonicus, 1.9 to $20.2 \mathrm{~mm}$ for $E$. coccineum, 4.9 to $35 \mathrm{~mm} D$. juncea and 4.3 to $33.5 \mathrm{~mm}$ for L. hirsuta.

\section{Biomass production}

\section{Plant volume growth and biomass components}

Harvesting intensity had a positive effect on the mean annual increment of plant biomass volume for all species except for E. coccineum (Fig. 3). D. juncea and L. hirsuta exhibited the highest mean growth rates and the highest response to harvesting intensity. In both cases, variability in plant volume growth was higher in the medium-productivity site (Table S1-2). The response of S. patagonicus varied with site productivity being less responsive in the 
Fig. 2 Observed stem volume vs. predicted stem volume showing the goodness of fit of the volume models developed for resprouts of five north Patagonian native species. The selected model for each species is given in each plot. Volume of steams ( $\mathrm{SV}$ in $\mathrm{cm}^{3}$ ) was predicted as a function of linear and quadratic terms of steam basal diameter (SBD in $\mathrm{mm}$ ) and height (H in $\mathrm{m}) .(*)$ VarPower function was used to model unequal variances
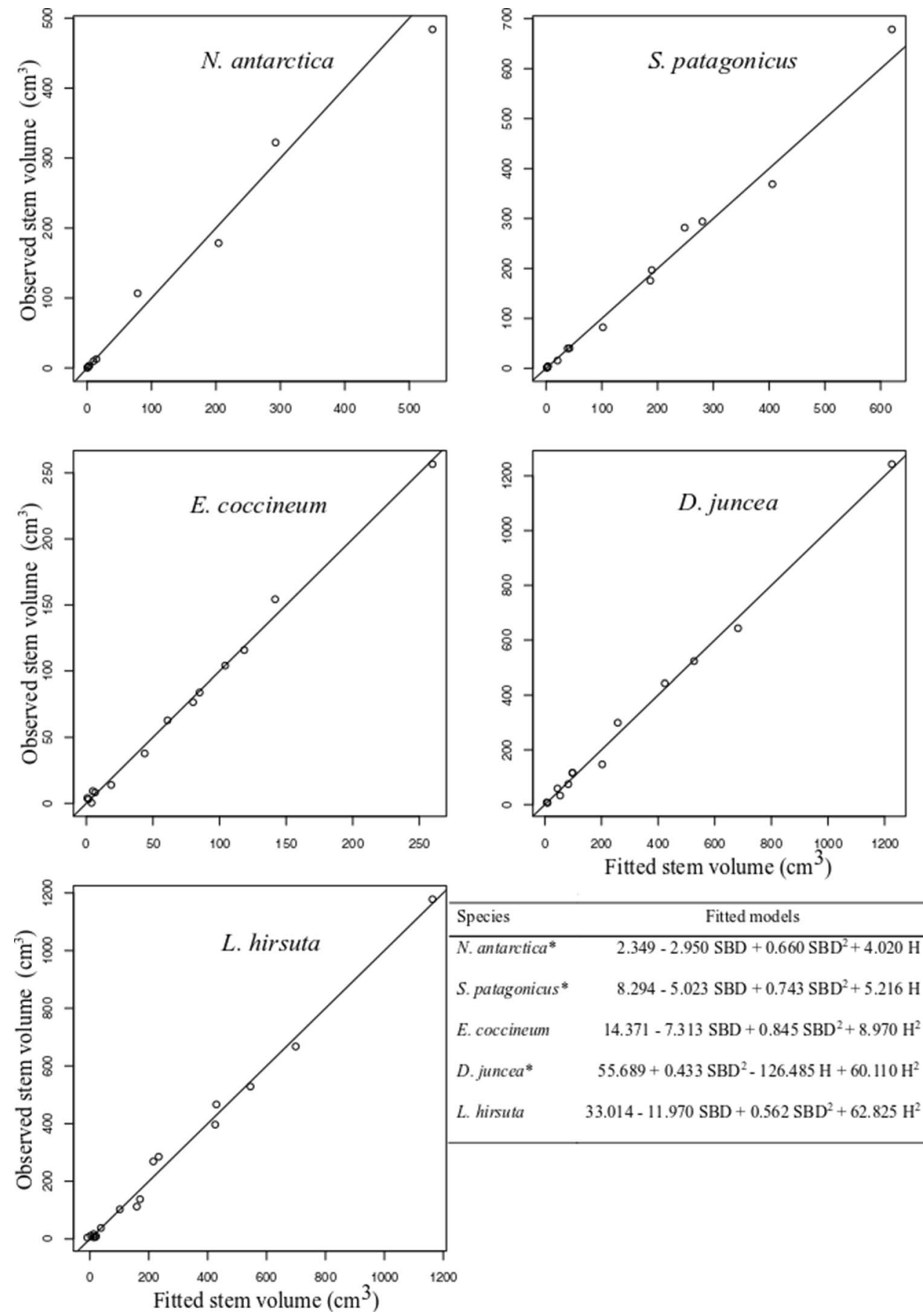

medium-productivity site. $N$. antarctica showed an intermediate response to harvesting intensity that interacted with site productivity denoting a lower response on the lowproductivity site. E. coccineum, on the contrary, showed no response to harvesting intensity neither to site productivity.

Plant volume increment was the result of stem volume and number of stems per plant (Supplementary material, Table S1-3, Table S1-4). The species analyzed responded in diverse, and often nonlinear, ways to harvesting intensity for the different analyzed variables, denoting several strategies for obtaining resources. For example, N. antarctica showed bigger stems, but no changes in stems per stool when harvesting intensity increased. Therefore, the plant response to harvesting intensity in this species was mainly due to the bigger size of the resprouts. $S$. patagonicus response was complex because harvesting intensity produced bigger stems, but the number of stems per plant responded in a nonlinear way and interacted with site, with higher positive effect of harvesting intensity in the medium-productivity site. Indeed, the plant volume of this species exhibited a stronger correlation with the stem volume 

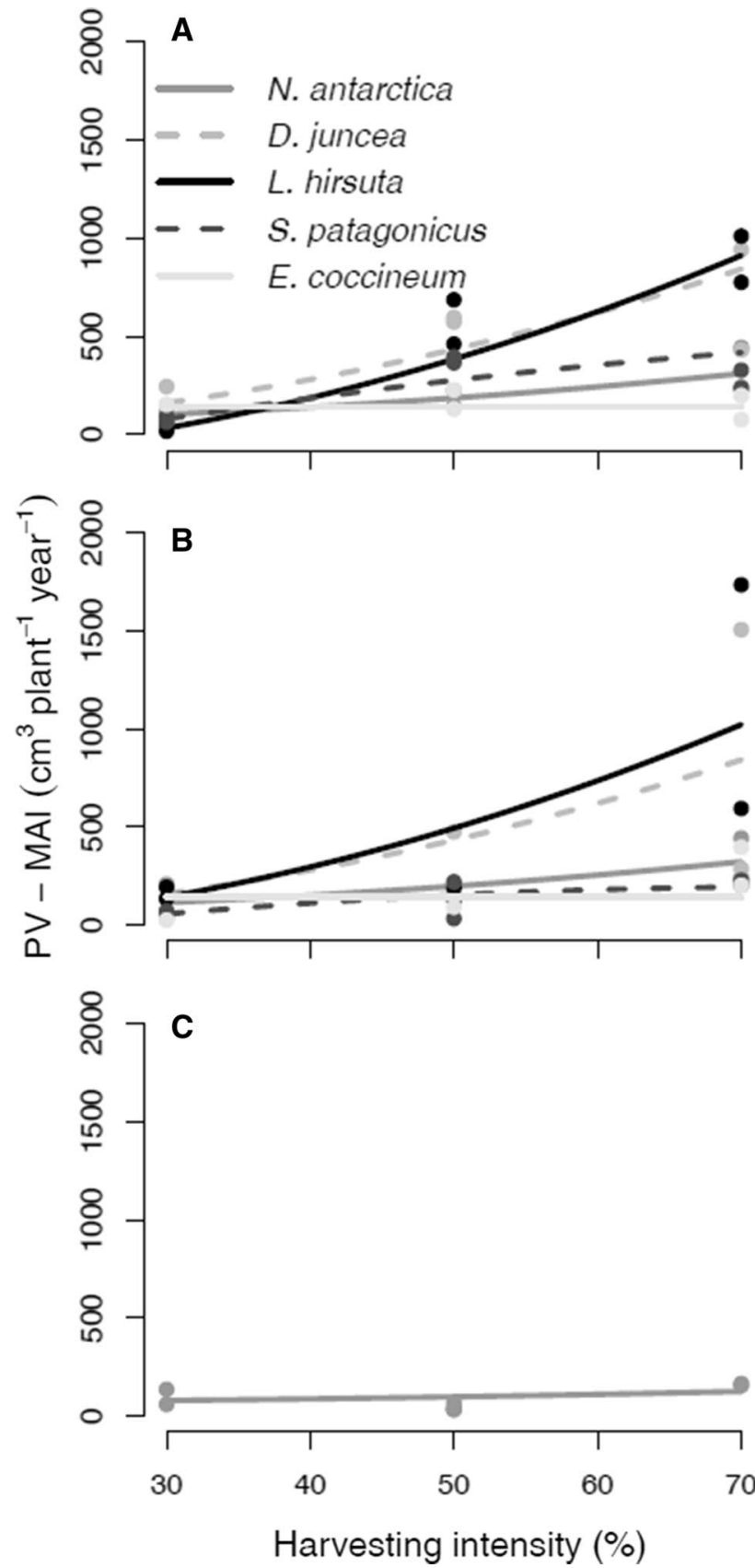

Fig. 3 Mean annual increment of plant volume coppice biomass under a harvesting intensity gradient for five native species of northern Patagonia shrublands. a High-productivity site, b medium-productivity site, $\mathbf{c}$ low-productivity site

and their response to harvesting intensity (Supplementary material, Table S1-5). L. hirsuta responded positively in both number of stems and size, with the plant volume production highly correlated with number of stems. D. juncea also showed more biomass per plant mainly due to bigger resprouts. In $E$. coccineum, harvesting intensity had a positive effect on stem volume and the number of stems per plant response interacted with site being more positive in the medium-productivity site.

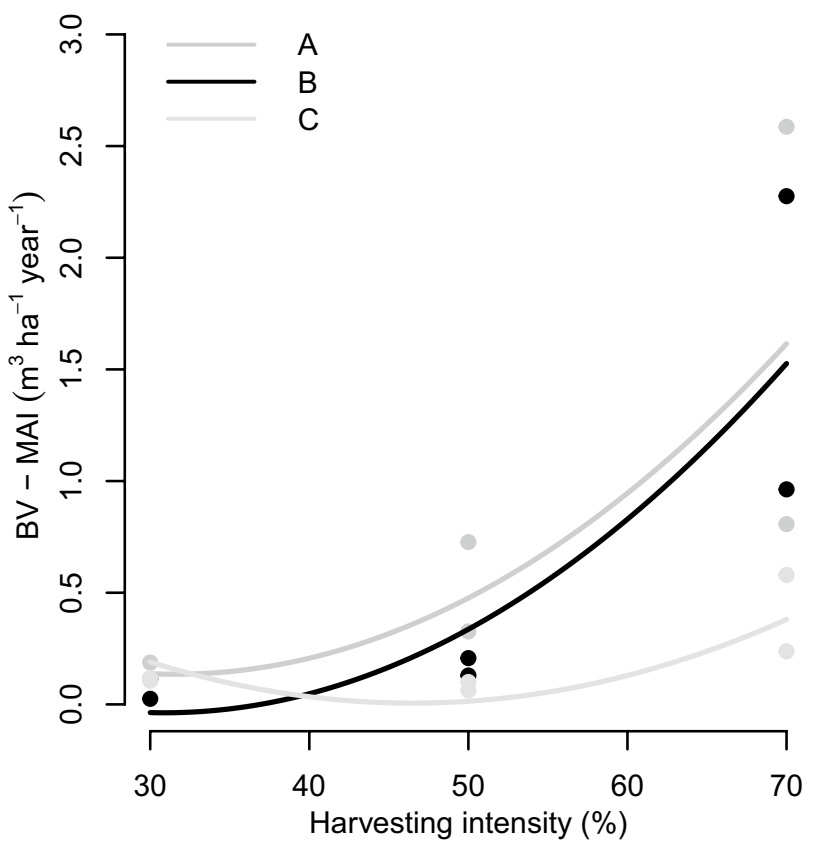

Fig. 4 Mean annual increment of coppice biomass volume per hectare under a harvesting intensity gradient for three contrasting shrublands in northern Patagonia. A: high-productivity site, B: mediumproductivity site, $\mathrm{C}$ : low-productivity site

Nonetheless, neither site, neither harvesting intensity, where selected as predictors of plant volume increment by AIC criteria in this species. In fact, both predictors show low levels of importance for predicting biomass production in this species (Supplementary material, Table S1-4).

Independently of the harvesting level, biomass production was higher for $D$. juncea and $L$. hirsuta than the rest of the species due to bigger stems (Supplementary material, Fig. S1-1). $N$. antarctica had more stems per stool in the low-productivity site, but these were smaller.

\section{Mean annual biomass production}

Harvesting intensity modified coppice biomass annual production in all the sites. The high- and medium-productivity sites showed similar responses, with harvesting intensity enhancing biomass production significantly (Fig. 4; Supplementary material, Table S1-6 for fitted model). In the low-productivity site, the biomass production and the response to harvesting intensity were much less accentuated.

\section{Discussion}

\section{Plant volume growth and biomass components}

In the present study, we analyzed how biomass production of the most important coppicing species of northern 
Patagonia shrublands was affected by harvesting intensity and site condition between 3 and 4 years after intervention. Harvesting intensity had a significant effect on stem dimensions, number of stems per stool and therefore biomass production per resprouting plant or stool. Often, the biomass component showed a nonlinear response to harvesting intensity.

Our work denotes that site was important in defining stem dimensions, while harvesting intensity largely affected the number of stems per stool and biomass production per resprouting plant except for $N$. antarctica and E. coccineum where harvesting intensity had an equal or higher importance as site in stem dimensions (Supplementary material, Table S1-4). These results agree with previous studies in other Mediterranean species that denoted that light availability regulates lateral growth by reducing sprout recruitment, and soil nutrient content (a measure of site quality) limits plant's vertical growth (Vila and Terradas 1995; Gracia and Retana 2004). In general, the plant volume growth of $N$. antarctica, D. juncea and $S$. patagonicus exhibited a stronger correlation with variations in stem dimensions, while L. hirsuta, and E. coccineum were more correlated with changes in the number of stems per stool (Supplementary material, Table S1-5). Previous works showed that stem dimensions in Quercus ilex not to be largely determined by coppice light availability (Gracia and Retana 2004), but Kobayashi et al. (1999) found a strong effect of canopy opening on juvenile resprouts diameter in Tectona grandis. In this sense, our results emphasize that coppicing species have different strategies for resource exploitation, mainly increasing light interception produced by canopy opening (Neke et al. 2006; Forrester et al. 2013). As other early successional species used for bioenergy purpose, northern Patagonia shrubland species exhibit fast juvenile growth rates with morphological adjustments that depend on the degree of resources liberation (Willebrand and Ledin 1993; Bond and Midgley 2001).

Independently of the harvesting intensity, species showed different sprouting strategies. While L. hirsuta and $D$. juncea had the largest resprouts mean growth, $N$. antarctica, the most studied species of those analyzed in this paper, increased the number of resprouts compensating relatively low-dimensional growth in the lowproductivity site (Supplementary material, Fig. S1-1). The higher fire frequency at the low-quality site (due to topographic position (Veblen and Lorenz 1987)) could explain the higher number of stems per stool also present in the remnant structure of the vegetation (Supplementary material, Table S1-1) (Bellingham and Sparrow 2013). The lower plant density in this site could also affect the number of stems per stool (Ashby et al. 1993; Benetka et al. 2007). Probably, future thinning of resprotus would be more important in low-productivity sites when a minimum diameter is needed for biomass commercialization (e.g., firewood) (Shackleton 2001; Neke et al. 2006). Nevertheless, the low growth rate observed in that site suggests that intensive management would not be sustainable under these environmental conditions. Probably, the rootto-shoot ratio of $N$. antarctica and other allometric partitioning relationships in this site are regulated by the site quality, where allocation to roots became more important under this condition for ensuring the species persistence (Bond and Midgley 2001; Gargaglione et al. 2010).

The previous work carried out in old shrublands (80 years) in our study area (Gyenge et al. 2008) found that $N$. antarctica and $L$. hirsuta had higher growth rates $(2.9 \mathrm{~mm}$ radial growth) than $S$. patagonicus and $D$. juncea (less than $1 \mathrm{~mm}$ ). According to our study, L. hirsuta and D. juncea are the most productive species, probably due to the stages of development that were considered. Higher growth rates are expected in earlier stages of development (Willebrand and Ledin 1993) with respect to later ones, where growth rate decreases as a result of the asymptotical growing pattern of resprouting species (Botequim et al. 2014; Serapiglia et al. 2014; Tiribelli et al. 2018); thus, these species could be exhibiting signs of senescence at an 80-year-old stand. Probably, different species could have different growing patterns, so productivity ranking between them could change with stand age.

While volume equations for these species have been developed, in this study we focused on smaller stem dimensions. In this sense, our work complements previous studies (Reque et al. 2007; Gyenge et al. 2009) by adding equations to lower diameter classes. This is important because tree biomass allocation patterns differ with age (Gargaglione et al. 2010), and thus, allometric equations are not valid beyond the fit range (Huber et al. 2016). Overall, our models are the first attempt to estimate total volume of young resprouts of these species in northern Patagonia, resulting in an important contribution to forest management in the region, in particular, for coppice shrublands.

\section{Mean annual biomass production}

As harvesting intensity increased, there were two main effects. First, the number of plants resprouting increased. Second, the plant volume growth (PV-MAI) had a positive nonlinear response to increasing harvesting intensity, especially in both hillside sites. Together, they determined a strong positive effect of harvesting intensity on coppice biomass production at the plot level (community level) in these sites.

Our results agree with previous findings, such as those by Forrester et al. (2003). Working in Eucalyptus sieberi stands, these authors found a strong relationship between thinning 
intensity and coppice growth during the first years after treatment, concluding this resulted from increasing water and light availability. Nonetheless, when comparing site quality; coppice basal area was much lower in stands with higher site quality due to a lower fire frequency and the prevailing regeneration mechanism, seeds rather than resprouts.

Biomass production was relatively low compared with exotic species under short rotation coppice in Mediterranean regions, such as poplar (Kauter et al. 2003; Oliveira et al. 2018), but similar to other native woodlands (Mroz et al. 1985). Very few studies have focused on northern Patagonia shrubland productivity. Previous studies estimated $2413 \mathrm{~kg} \mathrm{ha}^{-1}$ year $^{-1}$ of dry stem biomass in shrublands of around 80 years old (Gyenge et al. 2008). Our model predicts an annual mean increment around $3043 \mathrm{~kg} \mathrm{ha}^{-1}$ year $^{-1}$ of dry stem biomass in the high- and medium-productivity sites, if the total of the biomass was harvested (i.e., extracting $100 \%$ of basal area). By using a wood density of $630 \mathrm{~kg} \mathrm{~m}^{-3}$ as these authors, the productivity of these sites would be in the range estimated by Gyenge et al. (2008). The differences between both estimations could be due to previously mentioned asymptotically growing patterns of these species and differences in species compositions. We did not perform $100 \%$ harvesting treatments so, although useful for comparison, the result of this extrapolation must be used cautiously.

Although the medium- and high-productivity sites were similar in shrubland age (estimated as time since fire) and composition (Table 1), we found strong differences in firewood production (even more than expected according to differences in resprouting growth rates). This could be explained by differences in height growth, which are expressed when plant competition starts. For instance, Gracia and Retana (2004) found that height growth in Quercus ilex varied with site quality and that differences increased over time. In our case, this is supported by the fact that sites differ in dominant height, which is an expression of site conditions (Gracia and Retana 2004; Skovsgaard and Vanclay 2008; Bahamonde et al. 2018). In fact, we found that in $N$. antarctica, the only species present in all sites, the stems height growth was higher in the high-productivity site.

Strip harvesting in north Patagonia shrublands represents a novel approach. Biomass productivity was only estimated by resprouting plants. The remnant stand was not incorporated in the biomass production model because it helps to maintain continuous forest cover which is key for ecosystem service provision as local legislation demands (National Law 26.331) (Coulin et al. 2019). This is especially important since forest management for energy purposes requires relatively short rotation periods, implying high ecological risks (Cavallero et al. 2015). However, it should consider that when designing harvesting cycles, subsequent interventions will be carried out on the remnant stand, and eventually, the entire stand will be represented by areas (strips) in different growth stages. For this, the established experiment, in the long term, will allow us to generate key information for the development of temperate shrubland management as has been proved by long-term experiments in European silviculture (Pretzsch et al. 2019). Local legislation does not permit clear-cuts of native forest; nonetheless, higher harvesting intensities favor biomass production, and therefore economic income from commercialization, exhibiting a tradeoff between conservation policy and productive objectives.

Our results go beyond biomass production. For example, harvesting biomass could also be an important management strategy for diminishing fuel continuity and wildfire hazard, the main disturbance in this type of Mediterranean ecosystems (Kitzberger and Veblen 1999), as has been largely studied for the Mediterranean basin (Madrigal et al. 2016). Our results agree that biomass harvesting in these ecosystems only reduces fire hazard in the short term because shrubland species recover quickly (Marino et al. 2011, 2014; Fernández and Vega 2014; Fernandes 2015; Madrigal et al. 2016) and mainly by a large bulk of fine fuels. In fact, our results show that increasing harvesting intensity of biomass (and potentially diminishing fuel continuity) produces a major production of fine fuel in the short term (potentiality increasing flammability); thus, this trade-off shows that the management of these communities for fire hazard reduction needs more complex solutions as previous works have discussed (Madrigal et al. 2016).

\section{Conclusions}

This is the first study quantifying the biomass production of northern Patagonia shrublands under a harvesting intensity gradient in contrasting site conditions. The coppice growth of shrublands showed a strong positive response to harvesting intensity in both north- and south-facing locations, suggesting that under these conditions canopy opening and, consequently, light availability become key for determining resprouting vigor. On the contrary, biomass production was low and unresponsive in the valley bottom where probably other resources modulate plant resprouting vigor, suggesting that intensive coppicing systems for biomass production are not viable in such environmental conditions. On the other hand, growth and harvesting intensity effect varied among species. In both hillside sites, $L$. hirsuta and $D$. juncea exhibited the highest growth rates under high harvesting intensity. Thus, intense management for biomass production should promote the cover of these species (e.g., through plantings or removing the competition from other species). Our approach can be also relevant to the management of other native shrublands worldwide, especially where scientific evidence is scarce. 
Acknowledgements We are grateful to the private forest owners for allowing us to install the experiments in their fields. We specially thank Y. Cardoso and A. Henry for field assistance at various stages and also, two anonymous reviewers for their comments. The study was funded by Agencia Nacional de Promoción Científica y Tecnológica-Argentina (PICT 2013-1079 and PICT 2016-0305), Universidad Nacional de Río Negro (PI-40-B-399) and a Consejo Nacional de Investigaciones Científicas y Técnicas-Argentina scholarship to the first author.

\section{References}

Abbasi T, Abbasi SA (2010) Biomass energy and the environmental impacts associated with its production and utilization. Renew Sustain Energy Rev 14:919-937. https://doi.org/10.1016/j. rser.2009.11.006

Ashby WC, Bresnan DF, Kjelgren RK, Roth PL, Preece JA, Huetteman CA (1993) Coppice growth and water relations in silver maple. Biomass Bioenergy 5:317-323

Avohou TH, Houehounha R, Glele-kakai R, Ephrem A, Sinsin B (2010) Firewood yield and profitability of a traditional Daniellia oliveri short-rotation coppice on fallow lands in Benin. Biomass Bioenergy 35:562-571. https://doi.org/10.1016/j.biombioe.2010.10.030

Bahamonde HA, Pastur GM, Lencinas MV, Soler R, Rosas YM (2018) The relative importance of soil properties and regional climate as drivers of productivity in southern Patagonia's Nothofagus antarctica forests. Ann For Sci. https://doi.org/10.1007/s1359 5-018-0725-7

Bartoń K (2019) Multi-model inference. R package version 1.43.15 https://cran.r-project.org/web/packages/MuMIn/MuMIn.pdf. Accessed 4 July 2019

Bellingham PJ, Sparrow AD (2013) Resprouting as a life history strategy in woody plant communities. Oikos 89:409-416. https://doi. org/10.1034/j.1600-0706.2000.890224.x

Benetka V, Vrátný F, Šálková I (2007) Comparison of the productivity of Populus nigra L. with an interspecific hybrid in a short rotation coppice in marginal areas. Biomass Bioenergy 31:367-374. https ://doi.org/10.1016/j.biombioe.2007.01.005

Bond WJ, Midgley JJ (2001) Ecology of sprouting in woody plants: the persistence niche. Trends Ecol Evol 16:45-51

Botequim B, Zubizarreta-Gerendiain A, Garcia-Gonzalo J, Silva A, Marques S, Fernandes PM, Pereira JMC, Tomé M (2014) A model of shrub biomass accumulation as a tool to support management of Portuguese forests. IForest 8:114-125. https://doi.org/10.3832/ ifor0931-008

Burnham KP, Anderson DR (2002) Model selection and multimodel inference: a practical information-theoretic approach. Springer, New York

Burnham KP, Anderson DR, Huyvaert KP (2011) AIC model selection and multimodel inference in behavioral ecology: Some background, observations, and comparisons. Behav Ecol Sociobiol 65:23-35

Cavallero L, López DR, Raffaele E, Aizen MA (2015) Structural functional approach to identify post-disturbance recovery indicators in forests from northwestern Patagonia: a tool to prevent state transitions. Ecol Indic 52:85-95. https://doi.org/10.1016/j. ecolind.2014.11.019

Chauchard L, Frugoni M, Novack C (2015) Manual de Buenas Practicas para el Manejo de las Plantaciones Forestales en la Region de la Patagonia Andina. Buenos Aires

Coulin C, Aizen MA, Garibaldi LA (2019) Contrasting responses of plants and pollinators to woodland disturbance. Austral Ecol. https://doi.org/10.1111/aec.12771

Cruz De León G, Uranga-Valencia LP (2013) Theoretical evaluation of Huber and Smalian methods applied to tree stem classical geometries. Bosque 34:311-317. https://doi.org/10.4067/S0717 $-92002013000300007$

Dezzotti A, Sancholuz L (1991) Los bosques de Austrocedrus chilensis en Argentina: ubicación, estructura y crecimiento. Bosque $12: 43-52$

European Commissio (2003) Directive 2003/87/EC of the European Parliament and of the Council of 13 October 2003. Off J Eur Union 275:32-46 (Annex IV)

FAO (2008) Bosques y energía Cuestiones clave, Roma

Fernandes PM (2015) Empirical support for the use of prescribed burning as a fuel treatment. Curr For Rep 1:118-127

Fernández C, Vega JA (2014) Shrub recovery after fuel reduction treatments and a subsequent fire in a Spanish heathland. Plant Ecol 215(11):1233-1243

Forrester DI, Bauhus J, Connell M (2003) Competition in thinned Silvertop Ash (Eucalyptus sieberi L. Johnson) stands from early coppice growth. For Ecol Manage 174:459-475

Forrester DI, Collopy JJ, Beadle CL, Baker TG (2013) Effect of thinning, pruning and nitrogen fertiliser application on light interception and light-use efficiency in a young Eucalyptus nitens plantation. For Ecol Manage 288:21-30. https://doi. org/10.1016/j.foreco.2011.11.024

Gargaglione V, Peri P, Rubio G (2010) Allometric relations for biomass partitioning of Nothofagus antarctica trees of different crown classes over a site quality gradient. For Ecol Manage 259:1118-1126. https://doi.org/10.1016/j.foreco.2009.12.025

Garibaldi LA, Aristimuño FJ, Oddi F, Tiribelli FJ (2017) Inferencia multimodelo en ciencias sociales y ambientales. Ecol Austral. https://doi.org/10.25260/EA.17.27.3.0.513

Glithero N, Wilson P, Ramsden S (2013) Prospects for arable farm uptake of short rotation coppice willow and miscanthus in England. Appl Energy 107:209-218

Goldenberg MG, Gowda JH, Casas C, Garibaldi LA (2018) Efecto de la tasa de descuento sobre la priorización de alternativas de manejo del matorral Norpatagónico argentino. Bosque 39:217226. https://doi.org/10.4067/S0717-92002018000200217

González-González BD, Sixto H, Alberdi I, Esteban L, Guerrero S, Pasalodos M, Vázquez A, Cañellas I (2017) Estimation of shrub biomass availability along two geographical transects in the Iberian Peninsula for energy purposes. Biomass Bioenergy 105:211-218. https://doi.org/10.1016/j.biombioe.2017.07.011

Gracia M, Retana J (2004) Effect of site quality and shading on sprouting patterns of holm oak coppices. For Ecol Manage 188:39-49. https://doi.org/10.1016/j.foreco.2003.07.023

Gyenge J, Fernández ME, Sarasola M, Schlichter T (2008) Testing a hypothesis of the relationship between productivity and water use efficiency in Patagonian forests with native and exotic species. For Ecol Manage 255:3281-3287. https://doi. org/10.1016/j.foreco.2008.01.078

Gyenge J, Fernández ME, Sarasola M, De Urquiza M, Schlichter T (2009) Ecuaciones para la estimación de biomasa aérea y volumen de fuste de algunas especies leñosas nativas en el valle del río Foyel, NW Patagonia Argentina. Bosque 30:95-101

Huber JA, May K, Willow AÁ (2016) Allometric tree biomass models of various species grown in short-rotation agroforestry systems. Eur J For Res. https://doi.org/10.1007/s10342-016-1010-7

Karp A, Shield I (2014) Bioenergy from plants and the sustainable yield challenge. New Phytol 179:15-32. https://doi.org/10.111 1/j.1469-8137.2008.02432.x

Kauter D, Lewandowski I, Claupein W (2003) Quantity and quality of harvestable biomass from Populus short rotation coppice for solid fuel use-a review of the physiological basis and management influences. Biomass Bioenergy 24:411-427

Keeley JE, Pausas JG, Rundel PW, Bond WJ, Bradstock RA (2011) Fire as an evolutionary pressure shaping plant traits. Trends Plant Sci 16:406-411. https://doi.org/10.1016/j.tplants.2011.04.002 
Kitzberger T, Veblen TT (1999) Fire-induced changes in northern Patagonian landscapes. Landsc Ecol 14:1-15. https://doi. org/10.1023/A:1008069712826

Kobayashi S, Turnbull JW, Toma T, Mori T, Majid NMNA (1999) Rehabilitation of degraded tropical forest ecosystems: workshop proceedings, 2-4 November, Bogor, Indonesia, pp 151-156

Landesmann JB, Gowda JH, Kitzberger T (2016) Temporal shifts in the interaction between woody resprouters and an obligate seeder tree during a post-fire succession in Patagonia. J Veg Sci. https:// doi.org/10.1111/jvs. 12430

Madrigal J, Fernández-Miguela I, Hernando C, Guijarro M, VegaNieva DJ, Tolosana E (2016) Does forest biomass harvesting for energy reduce fire hazard in the Mediterranean basin? A case study in the Caroig Massif (Eastern Spain). Eur J For Res. https ://doi.org/10.1007/s10342-016-1004-5

Marino E, Guijarro M, Hernando C, Madrigal J, Diéz C (2011) Fire hazard after prescribed burning in a gorse shrubland: implications for fuel management. J Environ Manag 92:1003-1011

Marino E, Hernando C, Madrigal J, Guijarro M (2014) Short-term effect of fuel treatments on fire behaviour in a mixed heathland: a comparative assessment in an outdoor wind tunnel. Int J Wildland Fire 23:1097-1107

Mroz GM, Frederick DJ, Jurgensen MF (1985) Site and fertilizers effect on northern hardwood stump sprouting. Can J For 15(3):535-543

Neke KS, Owen-smith N, Witkowski ETF (2006) Comparative resprouting response of Savanna woody plant species following harvesting: the value of persistence. For Ecol Manage 232:114123. https://doi.org/10.1016/j.foreco.2006.05.051

Oliveira N, Rodríguez-soalleiro R, Pérez-cruzado C, Cañellas I, Sixto H, Ceulemans R (2018) Above- and below-ground carbon accumulation and biomass allocation in poplar short rotation plantations under Mediterranean conditions. For Ecol Manage 428:5765. https://doi.org/10.1016/j.foreco.2018.06.031

Pretzsch H, del Río M, Biber P, Arcangeli C, Bielak K, Brang P, Dudzinska M, Forrester DI, Klädtke J, Kohnle U, Ledermann T, Matthews R, Nagel J, Nagel R, Nilsson U, Ningre F, Nord-Larsen T, Wernsdörfer H, Sycheva E (2019) Maintenance of long-term experiments for unique insights into forest growth dynamics and trends: review and perspectives. Eur J Forest Res 138:165-185. https://doi.org/10.1007/s10342-018-1151-y

R Foundation for Statistical Computing, R Core Team (2020) https:// www.r-project.org. Accessed 1 Mar 2020

Regos A, Aquilué N, López I, Codina M, Retana J, Brotons L (2016) Synergies between forest biomass extraction for bioenergy and fire suppression in mediterranean ecosystems: insights from a storyline-and-simulation approach. Ecosystems 19:786-802. https ://doi.org/10.1007/s10021-016-9968-Z

Reque JA, Sarasola M, Gyenge J, Fernández ME (2007) Caracterización silvícola de ñirantales del norte de la Patagonia para la gestión forestal sostenible. Bosque 28:33-45
Rusch VE, Rusch GM, Goijman AP, Varela S, Claps L (2017) Ecosystem services to support environmental and socially sustainable decision-making. Ecol Austral 27:162-176

Pinheiro J, Bates D, DebRoy S, Sarkar D, EISPACK, Heisterkamp S, Van Willigen B, R Core Team (2020) nlme: linear and nonlinear mixed effects models. R package version 3.1-144. https://svn.rproject.org/R-packages/trunk/nlme. Accessed 2 Mar 2020

Serapiglia MJ, Gouker FE, Smart LB (2014) Early selection of novel triploid hybrids of shrub willow with improved biomass yield relative to diploids. BMC Plant Biol 14:74

Shackleton CM (2001) Managing regrowth of an indigenous savanna tree species (Terminalia sericea) for fuelwood: the influence of stump dimensions and post-harvest coppice pruning. Biomass Bioenergy 20:261-270

Skaug H, Fournier D, Nielsen A, Magnusson A, Bolker B (2016) Generalized linear mixed models using AD Model builder. $\mathrm{R}$ package version 0.8.3.3.15. http://glmmadmb.r-forge.r-project.org. http:// admb-project.org. Accessed 5 Mar 2020

Skovsgaard JP, Vanclay JK (2008) Forest site productivity: a review of the evolution of dendrometric concepts for even-aged stands. Forestry 81:13-31. https://doi.org/10.1093/forestry/cpm041

Speziale KL, Ruggiero A, Ezcurra C (2010) Plant species richnessenvironment relationships across the Subantarctic-Patagonian transition zone. J Biogeogr 37:449-464. https://doi.org/10.111 1/j.1365-2699.2009.02213.x

Spinelli R, Pari L, Aminti G, Magagnotti N, Giovannelli A (2017) Mortality, re-sprouting vigor and physiology of coppice stumps after mechanized cutting. Ann For Sci 74:5. https://doi.org/10.1007/ s13595-016-0604-Z

Tiribelli F, Kitzberger T, Morales JM (2018) Fire succession promote alternative stable states and positive fire-vegetation feedbacks. J Veg Sci. https://doi.org/10.1111/jvs.12620

USDA-Natural Resources Conservation Service (2014) Keys to soil taxonomy, 12th edn. Washington

Veblen TT, Lorenz DC (1987) Post-fire stand development of Austrocedrus-Nothofagus forests in northern Patagonia. Vegetation 71(2):113-126

Vila M, Terradas J (1995) Effects of nutrient availability and neighbours on shoot growth, re-sprouting and flowering of Erica multiflora. J Veg Sci 6(3):411-416

Willebrand EVA, Ledin S (1993) Willow coppice systems in short rotation forestry: effects of plant spacing, rotation length and clonal composition on biomass production. Biomass Bioenergy $4: 323-331$

Publisher's Note Springer Nature remains neutral with regard to jurisdictional claims in published maps and institutional affiliations. 